\title{
Investigation on degradation mechanism of polymer blockages in unconsolidated sandstone reservoirs
}

https://doi.org/10.1515/epoly-2020-0006

Received August 29, 2019; accepted November 26, 2019.

Abstract: Polymer flooding technology has shown satisfactorily acceptable performance in improving oil recovery from unconsolidated sandstone reservoirs. The adsorption of the polymer in the pore leads to the increase of injection pressure and the decrease of suction index, which affects the effect of polymer flooding. In this article, the water and oil content of polymer blockages, which are taken from Bohai Oilfield, are measured by weighing method. In addition, the synchronous thermal analyzer and Fourier transform infrared spectroscopy (FTIR) are used to evaluate the composition and functional groups of the blockage, respectively. Then the core flooding experiments are also utilized to assess the effect of polymer plugs on reservoir properties and optimize the best degradant formulation. The results of this investigation show that the polymer adsorption in core after polymer flooding is $0.0068 \mathrm{~g}$, which results in a permeability damage rate of $74.8 \%$. The degradation ability of the agent consisting of $1 \%$ oxidizer SA-HB and $10 \% \mathrm{HCl}$ is the best, the viscosity of the system decreases from 501.7 to $468.5 \mathrm{mPa} \cdot \mathrm{s}$.

Keywords: polymer; blockage; degradation mechanism; unconsolidated sand; EOR

\section{Introduction}

Polymer flooding has shown application prospects in enhancing oil recovery due to the outstanding ability of

\footnotetext{
* Corresponding author: Dong Zhang, Key Laboratory of Enhanced Oil Recovery (Northeast Petroleum University), Ministry of Education, Daqing, Heilongjiang, 163318, China, email: zhangdong084@163.com

Wenting Dong, Keliang Wang and Yue Qiu, Key Laboratory of Enhanced Oil Recovery (Northeast Petroleum University), Ministry of Education, Daqing, Heilongjiang, 163318, China

Wenting Dong, CNOOC Energy Development Engineering Technology Branch, CNOOC Experimental Center, Bohai Experimental Center, Tianjin, 300452, China
}

expanding sweep volume and improving oil sweeping efficiency $(1,2)$. However, polymer flooding technology has some problems along with improving oil recovery in the unconsolidated sandstone reservoirs. On the one hand, the polymer usually reacts with ions in the sewage to form a blockage at the bottom of the injection well. On the other hand, the large specific surface area of the loose sandstone leads to an increase in the adsorption of the polymer on the surface of the clay mineral. The macromolecular polymers entangle each other and complex with the heavy metal ions in the formation to form blockages in the pores. Therefore, the polymer flooding is limited by the high injection pressure and low injection volume than the design due to the blockages (3-6).

In previous studies, different techniques have been applied to plug removal, which range from biodegradation, physical degradation and chemical reactions. In the biodegradation methods, microorganisms obtain nitrogen for survival and reproduction by decomposing $\mathrm{C}-\mathrm{N}$ groups in polymer polymers, which achieves the goal of plugging removal and improving formation permeability. Many advanced technologies, such as fracturing, ultrasonic, and high pressure water jets, can be used in physical degradation methods (3,7). Although the plugging removal mechanisms of these technologies are not the same, but they use physical methods to improve the conductivity of the reservoir. Chemical plugging removal is composed of strong oxidants or surfactants to decompose plugs for reducing viscosity and increasing fluidity. These plugging removal techniques have achieved some results in the petroleum oil production process. Therefore, it is necessary to evaluate the properties of polymer plugs to give an optimal method of plugging degradation $(8,9)$.

In this article, we analyzed the composition of two blockages from loose sandstone polymers in the Bohai Oilfield. The composition and functional groups of the blockages are evaluated by the synchronous thermal analyzer and FTIR, respectively. Moreover, the permeability reduction factor and microscopic 


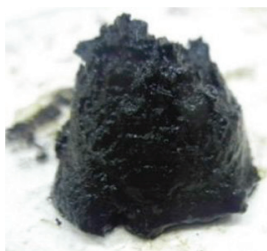

(a) Blocker A

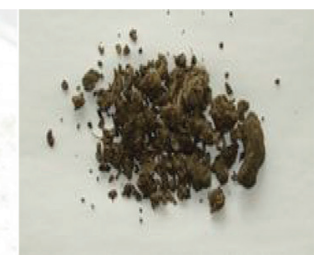

(b) Blocker B
Figure 1: Polymer blockage in loose sandstone.

morphology of blockages are systematically investigated. Finally, the agent consisting of $1 \%$ oxidizer SA-HB and $10 \% \mathrm{HCl}$ is suggested to degrade blockages.

\section{Materials and methods}

\subsection{Materials}

The blockage sample was taken from the LD10-1 oilfield polymer injection well, which are illustrated in Figure 1. Blocker A appears as a black solid with elastic properties containing a large amount of black oil, rock particles and polymer gel; blocker $B$ is a brown, loose and less elastic solid.

$\mathrm{HCl}, \mathrm{HF}$ and $\mathrm{HBF}_{4}$ were purchased from the inopharm Chemical Reagent Company (Shanghai, China). $\mathrm{K}_{2} \mathrm{~S}_{2} \mathrm{O}_{8}$, $\mathrm{NaClO}_{2},\left(\mathrm{NH}_{4}\right)_{2} \mathrm{~S}_{2} \mathrm{O}_{8}$ and $\mathrm{CaO}_{2}$ were produced by Languang Chemical Reagent Company (Chengdu, China). The viscosity reducer, which named SA-G is soluble in water and hydrocarbons. SA-G is an encapsulated solid chlorine dioxide that dissolves in water and is injected into the formation. Acid as initiator can release chlorine dioxide to act on the plug to achieve the purpose of plug removal. The experimental sewage used in this study is taken from the Bohai Oilfield and the ion compositions are shown in Table1.

\subsection{Composition of the polymer blockage}

The weighing method is used to measure the oil content and water content of the plug. Firstly, the quality of the plug was weighed and recorded as $M_{1}$. Then the plug was weighed again after drying and recorded as $\mathrm{M}_{2}$. The water content was calculated by Eq. 1. The plug solids, which were extracted from crude oil by toluene were weighed by a balance and recorded as $M_{3}$. The calculation of oil content is as follows (Eq. 2).

$$
\begin{gathered}
f_{w}=\frac{M_{1}-M_{2}}{M_{1}} \\
f_{o}=\frac{M_{1}-M_{2}-M_{3}}{M_{1}}
\end{gathered}
$$

Table 1: Ionic composition of water.

\begin{tabular}{lccccc}
\hline Ion & $\mathrm{Na}^{+}$ & $\mathrm{K}^{+}$ & $\mathrm{Ca}^{2+}$ & $\mathrm{Mg}^{2+}$ & $\mathrm{Cl}^{-}$ \\
\hline Concentration $(\mathrm{mg} / \mathrm{L})$ & 3327 & 36.7 & 41.8 & 21.8 & 3352 \\
\hline
\end{tabular}

The content of main elements in the blockages were determined by Energy Dispersive Spectrometer (EDS, Oxford Instruments Ltd, Oxford, England). The Fourier transform infrared spectroscopy (FTIR) spectra of the blockages were observed by a 1615 FTIR spectrometer (PerkinElmer, Waltham, MA, USA). Firstly, a small amount of dried olfactory potassium was added to the blockages powder, and then the mixture was loaded into the metal sheet to make a transparent sheet for testing the infrared absorption spectrum.

\subsection{Core damage experiment of the polymer blockage}

The cores with a length of $10 \mathrm{~cm}$ and a diameter of $2.5 \mathrm{~cm}$ were taken from the reservoir of the Bohai oilfield. The permeability of cores were measured by water, the values are 926 and $1217 \mathrm{mD}$. The experimental equipment mainly includes the displacement pump, the pressure collection system, the core holder, the middle container, which are all produced by Hai'an Petroleum Equipment Company, China. Saturate the core which is picked up the suction for $4 \mathrm{~h}$ with brine at a rate of $0.1 \mathrm{~mL} / \mathrm{min}$, the displacement pressure $P_{1}$. Then injecting 1.0 pore volume (PV) of polymer into the core and recording the pressure $\mathrm{P}_{2}$. The core permeability can be calculated by Darcy formula. Then, the core was dried and weighed to determine the polymer adsorption. Finally, the distribution of polymer in the pore space of the core after flooding was measured by a laser diffraction method (Mastersizer 2000, Malvern Instruments Ltd., Malvern, UK).

\subsection{Degradation experiment of the polymer blockage}

$5 \mathrm{~g}$ polymer plugs were added to $200 \mathrm{~mL}$ of different oxidant solutions, sealed and placed in a water bath at $60^{\circ} \mathrm{C}$ for $4 \mathrm{~h}$ to observe the degradation of the polymer.

\section{Results and discussion}

\subsection{Composition of the polymer blockage}

The drying and washing oil treatment to blockage, water content and oil content of polymer blockages can 
be calculated by the change of mass. The calculation results are shown as Table 2. It can be seen from the experimental data that the moisture content of blockage $\mathrm{A}$ is $42.62 \%$ and the oil content is $15.83 \%$, the moisture content of blockage B is $43.74 \%$, and the oil content is $18.94 \%$. Both polymer blockages have high water content and oil content.

The content of organic and inorganic components of the polymer blockages were analyzed by EDS according to the change of material weight during heating, which were illustrated in Table 3. As shown in Table 3, the organic matter component of the blockage A is mostly, and the inorganic component of the blockage $\mathrm{B}$ is mostly.

The FTIR spectra of the polymer blockages are illustrated in Figure 2. In the case of the polymer blockages, absorption peaks of groups such as amidegroups (-CONH2), - $\mathrm{CH} 2-$ and carboxyl groups (- $\mathrm{COO}-)$ are related to the polyacrylamide, it can be inferred that the main component of the plug used in the experiment is polyacrylamide.

Table 2: Water and oil content of polymer blockages.

\begin{tabular}{lccccc}
\hline Sample & $\mathbf{M}_{1}(\mathbf{g})$ & $\mathbf{M}_{2}(\mathbf{g})$ & $\mathbf{M}_{\mathbf{3}}(\mathbf{g})$ & $\begin{array}{c}\text { Water } \\
\text { content (\%) }\end{array}$ & $\begin{array}{c}\text { Oil } \\
\text { content (\%) }\end{array}$ \\
\hline Blockage A & 4.3186 & 2.4779 & 0.3922 & 42.62 & 15.83 \\
Blockage B & 6.7253 & 3.7837 & 0.7166 & 43.74 & 18.94 \\
\hline
\end{tabular}

Table 3: Organic and Inorganic content of polymer blockages.

\begin{tabular}{lcc}
\hline Sample & Organic content (\%) & Inorganic content (\%) \\
\hline Blockage A & 32.65 & 8.9 \\
Blockage B & 8.21 & 29.11 \\
\hline
\end{tabular}

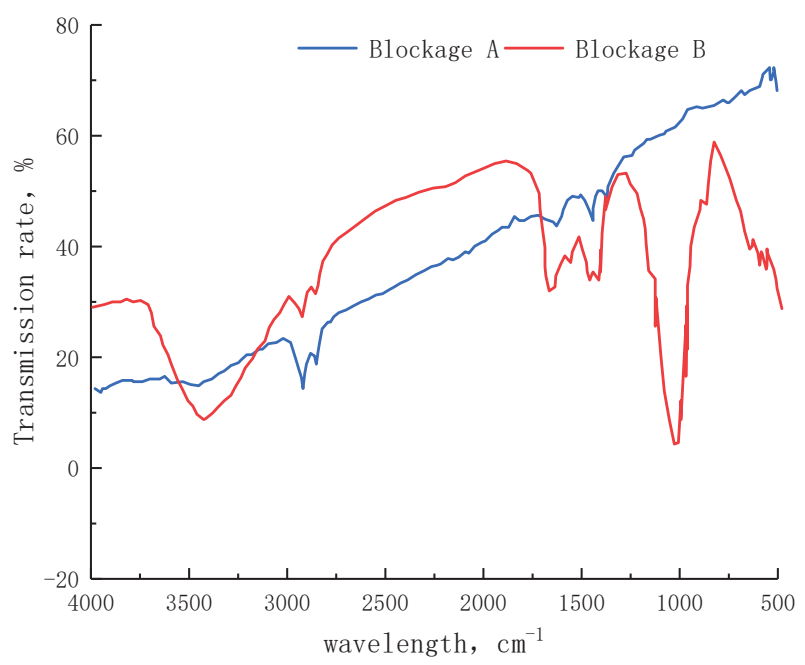

Figure 2: FTIR spectra of polymer blockages.

\subsection{Core damage of the polymer blockage}

The permeability changes of the core as the amount of polymer injected increases, which is used to determine core damage, are shown in Figure 3 and Table 4. The results show that the permeability damage rates of core A and core $\mathrm{B}$ are $74.8 \%$ and $67.9 \%$, respectively. It can be seen that the core permeability shows a significant decrease after the injection of the polymer solution. The lower the core permeability, the more serious the adsorption damage of polymer solution; when the core permeability is higher, this conclusion is contrary.

The retention of the polymer adsorption was examined by drying and weighing the core before and after the damage of the polymer. The experimental results are shown in Table 5. We compared the polymer adsorption in the cores, and the value of the core $\mathrm{A}$ and $\mathrm{B}$ are $0.0068 \mathrm{~g}$ and $0.0012 \mathrm{~g}$, respectively. It is concluded that the adsorption of the polymer in the core during the flooding process is more serious, and the adsorption capacity of the polymer in the low permeability core is slightly larger than that of the high permeability core, indicating the adsorption of the polymer and core pore structure is closely related.

The distribution structure of polymer at different positions of core was measured by SEM, which were illustrated in Figures 4 and 5, respectively. It can be seen from the figure that the polymer injected into the core is attached to the surface of the rock. In the middle of the core, the polymer attach to the rock surface in filaments, resulting in a gradual decrease in adsorption capacity. There are no obvious polymer was observed at the back end of the core. The results show that the damage of polymer is mainly concentrated in the near-well area. With the increase of injection depth, the adsorption of polymer decreases gradually.

\subsection{Degradation experiment of the polymer blockage}

\subsubsection{Effect of oxidant type}

Oxidant is the most effective agent for degrading polymer. In this paper, six kinds of oxidant degradation polymers such as $\mathrm{K}_{2} \mathrm{~S}_{2} \mathrm{O}_{8}, \mathrm{NaClO}_{2},\left(\mathrm{NH}_{4}\right)_{2} \mathrm{~S}_{2} \mathrm{O}_{8}, \mathrm{CaO}_{2}$ and SA-HB with mass concentration of $1 \%$ were selected (10). The polymer micelles were mixed with the oxidant solution for $4 \mathrm{~h}$ to observe the degradation of the polymer. The experimental conditions are shown in Table 6. It can be seen from the experimental results that $1 \% \mathrm{SA}-\mathrm{HB}$ has the strongest 


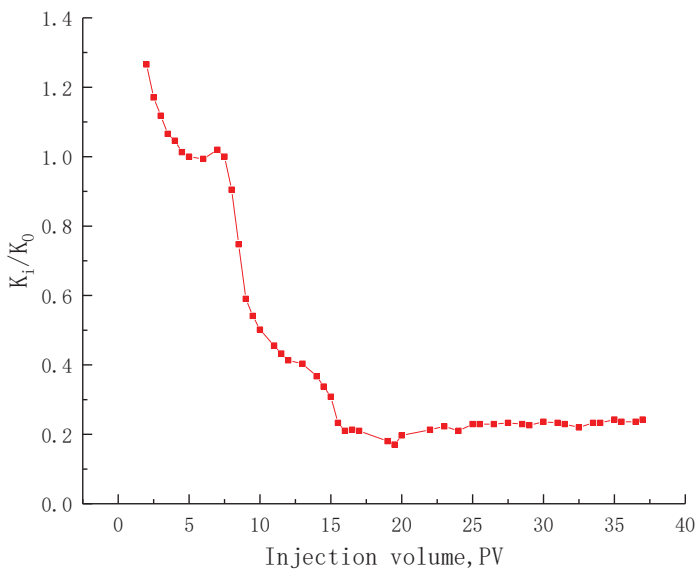

(a) Core 1

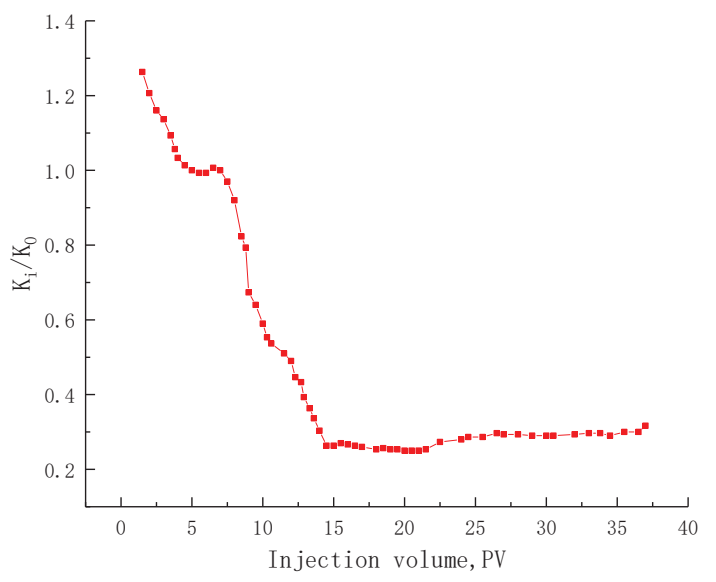

(b) Core 2

Figure 3: Permeability of cores at different polymer injection volume.

Table 4: Permeability damage rate.

\begin{tabular}{lllll}
\hline Sample & \multicolumn{3}{c}{ Ki/Ko (\%) } & $\begin{array}{l}\text { Damage } \\
\text { rate (\%) }\end{array}$ \\
\cline { 2 - 5 } & $\begin{array}{l}\text { Base } \\
\text { liquid }\end{array}$ & $\begin{array}{l}\text { Polymer } \\
\text { solution }\end{array}$ & $\begin{array}{l}\text { Base } \\
\text { liquid }\end{array}$ & \\
\hline Core A & 1.000 & 0.207 & 0.252 & 74.8 \\
Core B & 1.000 & 0.256 & 0.321 & 67.9 \\
\hline
\end{tabular}

Table 5: Comparison of core weight before and after polymer flooding.

\begin{tabular}{lccc}
\hline $\begin{array}{l}\text { Sample } \\
\text { name }\end{array}$ & $\begin{array}{c}\text { Weight before } \\
\text { damage }(\mathrm{g})\end{array}$ & $\begin{array}{c}\text { Weight after } \\
\text { damage }(\mathrm{g})\end{array}$ & $\begin{array}{c}\text { Weight } \\
\text { difference }(\mathrm{g})\end{array}$ \\
\hline Core A & 55.9936 & 55.0004 & 0.0068 \\
Core B & 52.6631 & 52.6643 & 0.0012 \\
\hline
\end{tabular}

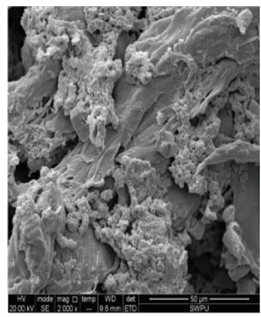

(a) Front

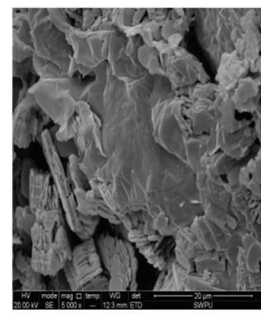

(b) Middle

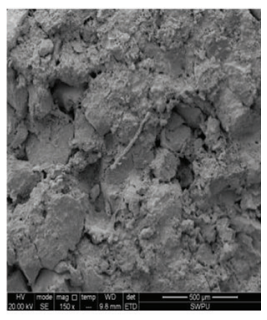

(c) Back
Figure 4: Microscopic structure of core A.

degradation ability to polymer micelles. After the reaction, the polymer micelles are dispersed and the crude oil floats above the liquid surface. Other oxidants can only degrade apart of polymer blockage, so that the effect is weaker than SA-HB.

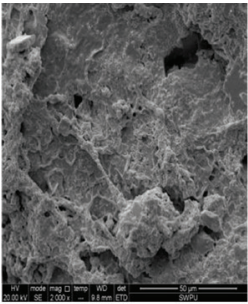

(a) Front

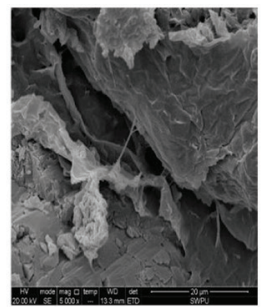

(b) Middle

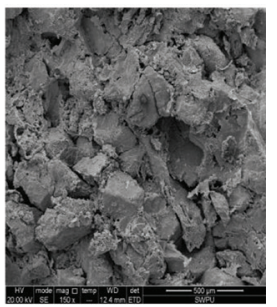

(c) Back
Figure 5: Microscopic structure of core B.

\subsubsection{Effect of acid solution}

The above experiment determined that SA-HB was the main agent of polymer degradation agent, and then the oxidant SA-HB was compounded with acid $\mathrm{HCl}$ to observe the degradation effect of the compound blockage removal system. The state of the object is shown in Table 7. The degradation efficiency of polymer plugs is affected by acid concentration. According to Table 7 , the compounding degradation agent can completely degrade the polymer micelle when the $\mathrm{HCl}$ concentration reaches $10 \%$, which is the optimum concentration.

\subsubsection{Effect of oxidant concentration}

The viscosity-reducing effect of the compounding agent on the polymer solution is evaluated by adding different concentrations of SA-HB. The viscosity of the system before and after degradation is shown in Table 8. It can be seen from the results that the degradation ability of 
Table 6: Degradation effect of oxidant.

\begin{tabular}{|c|c|c|c|c|c|}
\hline Oxidant & $\mathrm{K}_{2} \mathrm{~S}_{2} \mathrm{O}_{8}$ & $\left(\mathrm{NH}_{4}\right)_{2} \mathrm{~S}_{2} \mathrm{O}_{8}$ & $\mathrm{CaO}_{2}$ & $\mathrm{NaClO}_{2}$ & SA-HB \\
\hline $\begin{array}{l}\text { Experimental } \\
\text { phenomena }\end{array}$ & & & & 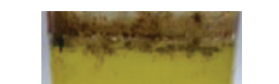 & 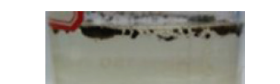 \\
\hline Polymer degradation & Mostly degradation & Mostly degradation & Mostly undegradation & Mostly undegradation & Complete degradation \\
\hline
\end{tabular}

Table 7: Degradation effect of different concentrations of $\mathrm{HCl}$.

\begin{tabular}{llll}
\hline Composite system & $1 \% \mathrm{SA}-\mathrm{HB}+8 \% \mathrm{HCl}$ & $1 \% \mathrm{SA}-\mathrm{HB}+10 \% \mathrm{HCl}$ & $1 \% \mathrm{SA}-\mathrm{HB}+12 \% \mathrm{HCl}$ \\
\hline Experimental phenomena & Partial degradation & Partial degradation & Complete degradation \\
Polymer degradation & &
\end{tabular}

Table 8: Degradation effect of different concentrations of SA-HB.

\begin{tabular}{lcc}
\hline $\begin{array}{l}\text { Compound } \\
\text { degradant type }\end{array}$ & $\begin{array}{c}\text { Initial viscosity } \\
(\mathrm{mPa} \cdot \mathbf{s})\end{array}$ & $\begin{array}{c}\text { Post-reaction } \\
\text { viscosity }(\mathrm{mPa} \cdot \mathbf{s})\end{array}$ \\
\hline $0.5 \% \mathrm{SA}-\mathrm{HB}+10 \% \mathrm{HCl}$ & 501.7 & 468.5 \\
$1.0 \% \mathrm{SA}-\mathrm{HB}+10 \% \mathrm{HCl}$ & 501.7 & 494.9 \\
$1.5 \% \mathrm{SA}-\mathrm{HB}+10 \% \mathrm{HCl}$ & 501.7 & 495.8 \\
$2.0 \% \mathrm{SA}-\mathrm{HB}+10 \% \mathrm{HCl}$ & 501.7 & 496.8 \\
\hline
\end{tabular}

the compounding degrading agent is enhanced with the increase of the concentration of SA-HB. When the concentration of SA-HB exceeds $1 \%$, the strengthening ability of the degradation ability is obviously weakened, and the viscosity of the system is decreased from 501.7 to $468.5 \mathrm{mPa} \cdot \mathrm{s}$.

\section{Conclusions}

The research aimed to identify the composition of polymer blockages in unconsolidated sandstone reservoirs. The water content of both polymer blockages are greater than $42.62 \%$ and the oil content were greater than $15 \%$. The characteristic absorption peaks of groups indicate that the main component of the plug is polyacrylamide. With the decrease of core permeability, the adsorption damage of polymer solution can reach more than $74.8 \%$. In addition, the degradation agent consisting of 1\% SA-HB with $10 \% \mathrm{HCl}$ has the strongest degradation ability, which reduces the viscosity from 501.7 to $468.5 \mathrm{mPa} \cdot \mathrm{s}$. Therefore, because of the degradation characteristics of plugging removal agent, it has great potential in improving oil recovery in unconsolidated sandstone reservoirs.

Acknowledgment: The project was supported by Youth Science Fund Project of Northeast Petroleum University (228QNC-37).

\section{References}

1. Wassmuth F.R., Arnold W., Green K., Cameron N., Polymer flood application to improve heavy recovery at East Bodo. J. Can. Petrol. Technol., 2009, 48(2), 55-61.

2. Alvarado V., Manrique E., Enhanced oil recovery: An update review. Energies, 2010, 3(9), 1529-1575.

3. Yadav U.S., Mahto V., Investigating the effect of several parameters on the gelation behavior of partially hydrolyzed polyacrylamide-hexamine-hydroquinone gels. Ind. Eng. Chem. Res., 2013, 52, 28, 9532-9537.

4. Andersen S.I., Birdi K.S., Influence of temperature and solvent on the asphaltenes. Petrol. Sci. Technol., 1990, 8(6), 593-615.

5. Seright R.S., Campbell A.R., Mozley P.S., Stability of partially hydrolyzed polyacrylamides at elevated temperatures in the absence of divalent cations. SPE J., 2010, 15, 341-348.

6. Fletcher A.J.P., Lamb S.P., Clifford P.J., Formation damage from polymer solutions: Factors governing injectivity. SPE Reservoir Eng., 1992, 7(2), 237-246. 
7. Levitt D., Slaughter W., Pope G., The effect of redox potential and metal solubility on oxidative polymer degradation. SPE Reserv. Eval. Eng., 2011, 14(3), 287-298.

8. Dominguez J.G., Retention and flow characteristics of polymer solutions in porous media. Soc. Petrol. Eng. Jamal, 2002, 25, 111-121.
9. Beyne A.O.E., The effect of pore blockage on the diffusivity in ZSM percolation approach. Chem. Eng. J., 2001, 82(1-3), 281-290.

10. Lu D.Y., Meng X.H., Wu W., Zhou J.Y., Analysis on the plugging for polymer mechanism and the removal technology flooding blocks in Bohai Sea. China Petrol. Chem. Stand. Quality, 2016, 28, 98-103. 